\title{
Research on Audit Early Warning System Frame under the Background of Financial Crisis
}

\author{
Xiaomei Luo ${ }^{1}$, Jin Yang ${ }^{1}$ \\ ${ }^{1}$ Sichuan Technology and Business College, Dujiangyan, 611830, China
}

Keywords: financial risk, audit function, early warning function, system construction

\begin{abstract}
Under the trend of integration of world economy and financial globalization, financial crisis is a disaster of the economy and society. Financial crisis is accumulated by the financial risks, how to prevent the financial risks and manage and control the financial risk accumulation process is an issue to be deeply researched. This paper is aimed to have a frame research on this issue, clear the research thought and method, propose the research framework system and innovation and have directional guidance to the deep research.
\end{abstract}

\section{Research Background, Status and Significance}

\section{Research background}

Currently in the world, the trend and characteristics of economic globalization and financial internationalization have been more and more obvious, and the economic and financial environments have also been more and more complicated. It is because of this kind of trend and characteristics that it is more possible to generate and accumulate financial risks, so as to trigger financial crisis, and even economic crisis.

The economic link in the world has been strengthened increasingly, the Southeastern Crisis in 1997 and the American subprime crisis in 2007 also comprehensively increased the risks in the financial industry of China, constituting great threat to the national economic security and financial stability. So we should strengthen the financial audit and supervision and functional coordination, make full use of the immune system function of the audit, guarantee the financial security of China, especially we should practically strengthen supervision to the accumulation process of financial risks to prevent the occurring of financial crisis. In terms of prevention of financial risks, scholars around the world are devoted to the theoretical research, and a lot of reformers are also carrying out practical reform. In this paper, it is proposed to construct a dynamic audit warning system to achieve the purpose of preventing the accumulation and transformation of financial risks in China in a certain extent through the system operation, so as to provide protection for the safe and stable development of finance and economy of China.

\section{Research status}

Audit has many functions such as "discovery", "revealing” and "prevention”, which should play their supervision role aimed at different audit functions, it is the basic function of audit to provide diagnosis support for the health of financial environment. In this paper, it is to make use of the advantages of audit to prevent financial risk, and propose the advantages and specific approaches of prevention of financial risks through audit (Yuan Ye, 2003; Meng Yan et al., 2009). After the subprime crisis triggered the financial crisis in 2007, the National Auditing Administration expressly proposed "theory on immune system function of audit:" (Liu Jiayi, 2008), emphasizing the role of audit in the prevention of financial risks.

In the practical reform, the preventive function of audit to the financial risk should play its due role. After the Southeastern Financial Crisis in 1997, the G7 Group set up Financial Stability Forum (FSF), and established ISA International Audit Standard System for the purpose of using this standard to make full use of the "regulatory role" function of audit. Aimed at how to apply ISA International Audit Standard System to realize the regulatory role and risk warning function of audit, some researches proposed the establishment of "standards-surveillance-compliance" system, which is called the golden rule of audit-guarantee of financial security, playing a guidance role in the audit practice. 
After the Southeastern Financial Crisis in 1997, the public did not blame the audit, but the financial regulatory authority and credit rating agency. However, behind this "silence”, it is actually predicted that the audit career faces the real career demand crisis. Just as Bromwich Hopwood pointed out, to be developed continuously and successfully, the audit career must face the challenges that are faced in different periods, and it is required to mine the fundamental problem to make the social roles and functions of the audit adapt to the characteristics in different periods. Therefore, the financial "regulatory role" of audit should be a dynamic concept, which should adapt to the change of global financial environment in different periods, so as to make adjustment and improvement continuously.

\section{Research significance}

Under the background of world economy integration and development transformation of the Chinese economy, it is theoretically significant to take the audit as an important part of financial risk prevention system to research its function and construct the dynamic audit warning system, with a significant application value, specifically reflected in the following:

(1) Deepen audit immune system theory, dynamic audit and dynamic audit warning theory research. After Liu Jiayi, director of the National Auditing Administration proposed the audit immune system theory, taking this as an indicator, the National Auditing Administration further deepened the implementation function of the national audit, strengthened the reform of national auditing function, expanded its function and enhanced the prevention function of the audit as the fire wall to resist the financial risk. On this basis, the theory frame of dynamic audit is set up, and the basic thought of dynamic audit warning theory is proposed, which deepens the audit immune system theory and further improves the audit theory frame.

(2) Discuss the internal mechanism and realization approach and the integrated exploration from theoretical innovation to practical application for the functional implementation of dynamic audit warning system. On the basis of theoretical research, it is to explore the internal mechanism and realization approach of dynamic audit warning. It is the basic requirement of scientific research to be from theory to practical application, and the theory is applied in the practice to realize a complete transformation.

(3) Establish dynamic audit warning system, realize the innovation of audit technical tools. On the basis of applying the current audit technology and tools, attempt to adopt new technical means and methods and innovate the audit technology and tools, so as to reduce the audit cost, maximize the national audit function and improve the audit efficiency.

(4) Research the implementation mechanism of dynamic audit warning system and realize the prevention of audit regulation to financial risks. Sort out the implementation mechanism of dynamic audit warning system, analyze and research the condition restricting and limiting the system implementation, such as implementation environment, so as to clear away the systematic and structural obstacles.

\section{Research Design and Methods}

\section{Research design}

The research design thought is as follows: under the overall background of financial crisis, analyze the new characteristics of economic environment and financial environment, as well as the development and innovation of information technology, so as to provide technology and necessary possibility for the construction of dynamic audit warning system; through the systematic combing of the audit system, on the basis of the latest audit theory, audit immune system, it is to analyze the theoretical frame of dynamic audit warning theory, so as to provide theoretical support for the construction of dynamic audit warning system; in order to verify the effectiveness of systematic operation of the dynamic audit warning system, provide empirical data to verify the system effect; research the implementation mechanism of dynamic audit warning system, so as to provide environmental condition support for the operation of dynamic audit warning system. It is mainly to analyze the economic and financial environment, technical environment and the policy environment, so as to provide basis for the implementation of dynamic audit warning system. 


\section{Research method}

The research method in this paper is mainly divided into two levels: the first level is the research method running through the whole research process, which is an overall strategically suited research method, mainly including systematic research method and conclusion research method, which will guide the whole research work; the second level is literature view method, comparison analysis method, logic reasoning method and other empirical research methods to regulate the research method and case research, file research and data empirical verification, which is the specific method of this paper.

\section{Main Research Frame and Research Contents}

\section{Research frame}

The research frame is as shown in the figure below:

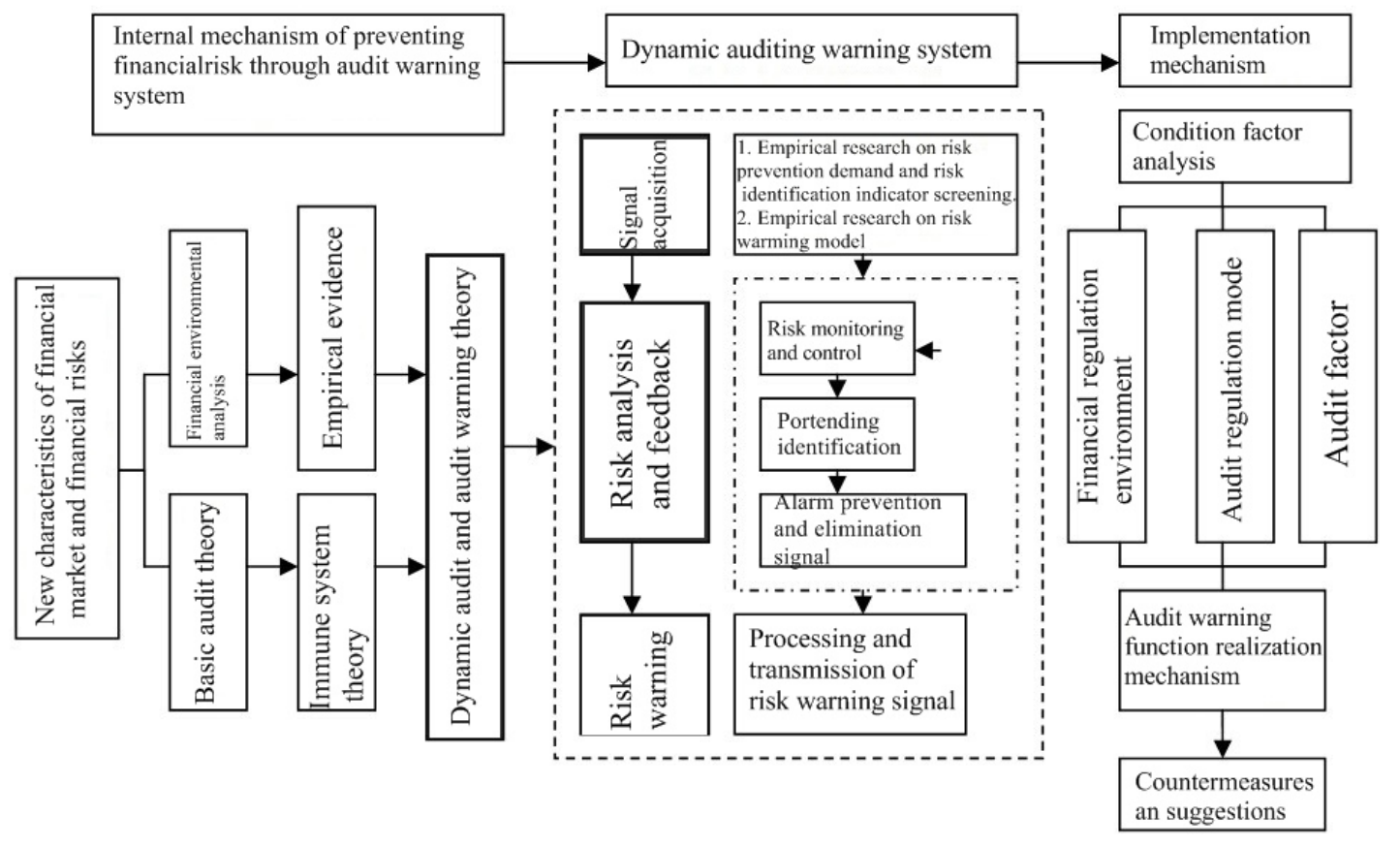

\section{Main research thoughts an contents}

(1) International mechanism of dynamic audit warning theory

The discovery, revealing and prevention functions of the audit can be effectively applied in the prevention of financial risks, and the construction of a dynamic warning system lies in the continuous monitoring to the formation process of financial risk effectively. In order to achieve the objective of preventing the macro and micro financial risks, it is required to carry out dynamic regulation and disposal to the relevant formation indicators of the financial risks, make the countermeasures to deal with the problems in time and intervene with the risk accumulation process.

(2) Empirical research on prevention of financial risks through audit

On one hand, obtain the support of relevant practitioners in understanding through investigation research, and establish the necessity analysis of dynamic audit warning system through the data analysis. On the other hand, screen the financial risks indicators through empirical analysis; verify the effectiveness of the dynamic audit warning system through the warning system of audit-preventing financial risk constructed and in combination with the economic data in the past several years, so as to ensure that the function of the system can be realized effectively.

(3) Construction and operation mechanism of dynamic audit warning system

Combine the financial audit with the financial regulation effectively, apply the modern information technology means to include the factors of the financial system that can effectively influence the financial risk in the audit regulation system, so as to effectively manage and control the accumulation process of these factors and achieve the objective of preventing financial risks. 
(4) Implementation mechanism of dynamic warning system

Establish a special national management regulation by starting from the reform of administrative system, include some functions of financial regulation and financial audit into the integrated management, strengthen the normal construction of financial audit through the new technical means, so as to include the financial audit and financial regulation in the process control and management.

\section{Main Concepts and Innovation Points of Research}

\section{Main research concepts}

(1) Under the background of economic globalization and transformation of the Chinese economy, the national audit regulatory authorities play the due "immune" function, which is an important strategy of national significance to the macro and micro economic risks. And the immune prevention function of audit makes the auditing regulation play a unique role in the financial regulation.

(2) The realization path of the audit-preventing financial risk is a dynamic audit warning system, which identifies the portending, sends out alarm prevention and elimination signal and outputs the risk signal according to the "risk identification-risk monitoring and feedback-risk warning", and meanwhile optimizes and upgrades the system according to the information fed back by the system.

(3) The core of dynamic audit warning system is the risk monitoring and feedback mechanism. In addition to using the dynamic warning technology such as the reasoning technology, adaptive feedback learning method and neural network method, the application of some traditional application technologies such as risk audit, extending audit and tracking audit will also further strengthen the improvement of dynamic audit warning mechanism.

\section{Innovation points of research}

The main innovation points are centrally reflected in three aspects:

(1) Construct the frame of dynamic audit theory on the basis of risk warning thought of audit immune system theory, propose the dynamic audit warning theory, and systematically explain the connotation, extension and possible application of the dynamic audit warning theory. The dynamic audit warning theory is the theoretical innovation contents of this paper, and is a completely new theory of conclusion and summarization on the basis of audit immune system theory, which further improves and develops the audit theory system, while providing theoretical basis for the construction of dynamic audit warning system.

(2) Construct the dynamic audit warning system of prevention of financial risks, explain the compositions and internal connection of such warning system. The dynamic audit system constructed is a regulation system with completely new significance formed based on the adjustment to the existing regulation system of the financial regulation department and financial institution in terms of financial risk. From the aspects of cost control and effectiveness of resource utilization, applying the basic structure and network of the existing financial regulation system can greatly reduce the cost of system construction on one hand, and on the other hand, it can also reform the mechanism and system conveniently. If a completely new system is constructed, it will take a huge amount of construction cost and mechanism and system reform cost, which is unbeneficial for the substantial implementation of this system, because it will involve in the problem who should bear and undertake the cost.

(3) Sort out the implementation mechanism of the dynamic audit warning system, propose the corresponding audit warning implementation model based on the specific environment. The main purpose of research on implementation mechanism of dynamic audit warning system is to provide public support in environment for the system construction and operation, the construction and operation of the system itself need the support of economic and financial environment, technical environment and policy environment. Through the environmental analysis, it is to clear away obstacles for the implementation of the system. 


\section{References}

[1] Chen Wenxia, Research on Construction of Financial Audit Warning System, Audit Research, Issue 2, 2011

[2] Chen Wejbin, Preliminary Research on Coordinative Framework of Financial Audit and Financial Regulation, China Audit, Issue 3, 2009

[3] Chen Qiuling, Xue Yuchun, Xiao Lu, Financial Risk Warning: Evaluation Indicator Warning Mechanism and Empirical Research, Journal of Shanghai University (social science edition), September 2009

[4] Cai Chun, Xie Zanchun, Sun Ting, Miao Lianqi, Role and Experience Reference of National Audit of G20 in Dealing with Financial Crisis [J], Audit Research, Issue 5, 2010

[5] Hu Liying, On Financial Audit and Financial Risk Prevention, Hebei Finance, Issue 7, 2006

[6] Gao Feng, New Trend of Development of International Financial Regulation and its Enlightenment to China [J], Journal of Central University of Science and Economics, Issue 6, 2001

[7] Liu Jiayi, Promoting Comprehensive Development of Audit Work under the Guidance of Scientific Outlook on Development, Audit Research, Issue 3, 2008

[8] Li Renhua, Realization Mechanism of Maintenance of National Financial Security through National Audit [J], Management World, Issue 2, 2010

[9] Lu Qiaoling, Establishment and Application of Decision-making Supporting System of Dynamic Audit, Shanghai Business, Issue 5, 2010

[10] Meng Yan, International Fluid Capital, Financial Security and Financial Audit Issue 6, 2009

[11] Pan Zhengyan, Functional Expansion of Financial Audit: Strengthening Social Supervision and Controlling Financial Risk, Audit and Economic Research, January 2008

[12] Tao Yulan, Thought on Introduction of “Immune System" to Financial Audit, Auditing and Financing, Issue 7, 2010

[13] Yu Ruizhen, Construction of Financial Regulation System from the Perspective of Financial Audit, Oriental Enterprise Culture, February 2011

[14] Yuan Ye, Earnestly Carrying out Spirit of the CPC $16^{\text {th }}$ National Congress, Making full Use of Role of Financial Audit, Issue 8, 2003. 